\title{
Principais aspectos da manipulação de oócitos inclusos em folículos ovarianos pré-antrais
}

\section{Main aspects of the manipulation of oocytes enclosed in preantral ovarian follicles}

\section{Aspectos principales de la manipulación de oocitos contenidos en folículos ováricos preantrales}

\author{
Marilu Constantino Max; ${ }^{1}$ Evelyn Rabelo de Andrade; ${ }^{2}$ Andrea Cristina Basso; ${ }^{3}$ \\ José Ricardo de Figueiredo; ${ }^{4}$ Marcelo Marcondes Seneda ${ }^{5}$
}

Departamento de Clínicas Veterinárias da Universidade Estadual de Londrina (UEL). Londrina, PR, Brasil

\section{Resumo}

Objetivo: Divulgar a biotécnica relacionando alguns de seus aspectos, bem como abordar suas principais etapas, o isolamento, a criopreservação e o cultivo. Fontes Consultadas: O levantamento das informações foi realizado no CAB, MEDLINE, PUBMED, Science Direct e Portal CAPES. Síntese dos Dados: Os folículos pré-antrais armazenam cerca de $90 \%$ dos oócitos presentes no ovário. Essa biotécnica consiste em recuperar oócitos imaturos retidos no interior de folículos pré-antrais antes de ocorrer o processo de atresia. Pela criopreservação destas células, é possível montar bancos de germoplasma preservando material genético de mulheres submetidas à quimio e/ou à radioterapia, e de animais em via de extinção. Conclusões: Por ser uma biotécnica recente, sua aplicação é restrita à pesquisa fundamental, sendo ainda necessário mais estudos para aprimorar suas etapas.

Palavras-chave: Biotecnologia. Técnicas reprodutivas. Oócitos, transplante. Folículo ovariano. Criopreservação.

\footnotetext{
${ }^{1}$ Graduanda do $5^{2}$ ano do Curso de Medicina Veterinária da UEL

${ }^{2}$ Doutoranda em Ciências Veterinárias da Faculdade de Veterinária da Universidade Estadual do Ceará. CRMV-PR 4608

${ }^{3}$ Doutoranda do Departamento de Medicina Veterinária Preventiva e Reprodução Animal da Universidade Estadual Paulista - UNESP, Campus Jaboticabal. CRMV-SP 10791

${ }^{4}$ Professor Doutor. Faculdade de Medicina Veterinária da Universidade Estadual do Ceará. CRMV-CE 1375

${ }^{5}$ Professor Doutor. Curso de Medicina Veterinária da UEL. CRMV-PR 5145
} 
MAX, M. C. et al. Manipulação de oócitos inclusos em folículos ovarianos. / Manipulation of oocytes enclosed in ovarian follicles. Manipulación de oocitos contenidos en folículos ováricos. Rev. Educ. Contin. CRMV-SP / Contin. Educ. J. CRMV-SP, São Paulo, v. 7 , n. $1 / 3$, p. $66-72,2004$.

\section{Introdução}

A biotecnologia da reprodução animal está em expressivo desenvolvimento, visando à maior eficiência da produção de animais domésticos, bem como aprimorar o conhecimento sobre a pesquisa fundamental da reprodução. Dentre as biotécnicas de maior impacto, podem-se destacar a inseminação artificial (IA), a transferência de embriões (TE), a produção in vitro de embriões (PIVE), a transgênese e a clonagem. Uma biotécnica mais recente consiste no aproveitamento dos folículos primordiais, por meio da técnica de manipulação de oócitos inclusos em folículos ovarianos pré-antrais (MOIFOPA) (Figura 1).

O estudo sobre os folículos pré-antrais (FOPA) tem merecido grande destaque nos últimos anos, não só pelo interesse em uma melhor compreensão da fisiologia folicular, mas pelos resultados diretos que o domínio desta técnica pode proporcionar. Pode-se considerar a crucial importância da conservação de germoplasma de espécies ameaçadas de extinção ou fêmeas de alto valor zootécnico subitamente mortas. Além disso, o modelo animal, especialmente a espécie ovina, serve como referência para estudos na espécie humana. A criopreservação de FOPA apresenta-se como forma de preservação de material genético para mulheres submetidas à quimio e/ou à radioterapia.

Para o aproveitamento dos folículos no estágio pré-antral, é necessária a adoção de um eficiente meio de cultivo, capaz de viabilizar o desenvolvimento folicular e a competência oocitária. A eficiência deste processo depende do progresso na elaboração dos meios de cultivo e da elucidação dos mecanismos celulares envolvidos na ativação e no crescimento dos folículos primordiais.

O objetivo dessa revisão é relacionar alguns aspectos dessa nova biotécnica. A abordagem será feita nas principais etapas, o isolamento, a criopreservação e o cultivo.

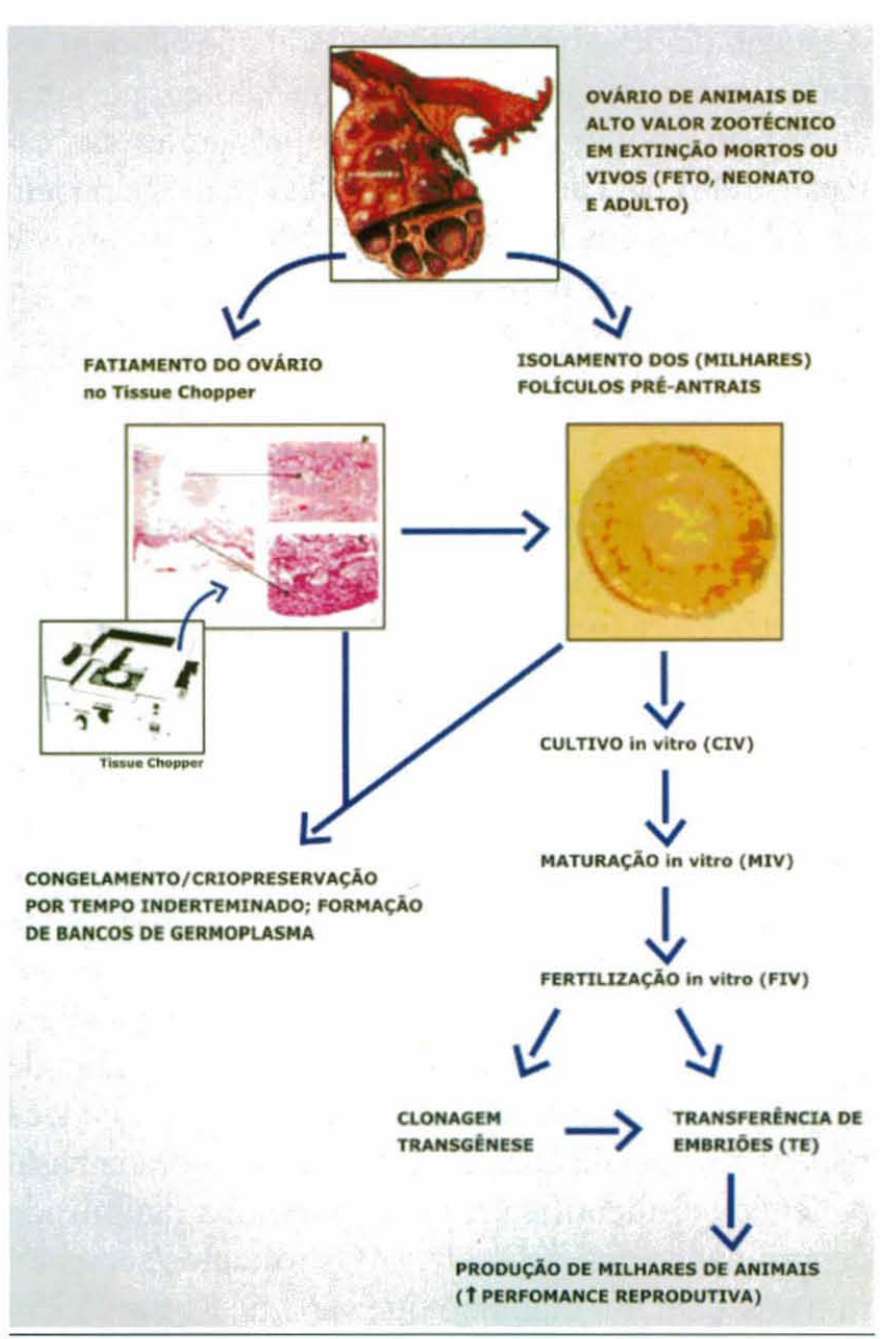

Figura 1 - Ilustração resumida das etapas da MOIFOPA e sua futura integração com outras biotécnicas da reprodução

\section{Revisão de Literatura}

\section{Caracterização dos Folículos Ovarianos}

Ao nascimento, as fềmeas de mamíferos apresentam ovários contendo milhares de folículos primordiais. ${ }^{1} \mathrm{Na}$ espécie bovina, a quantidade de folículos primordiais está estimada em 235.000 ou até $720.000{ }^{2,3}$ Nas espécies caprina, ovina e humana, os números variam de 37.646, 160.000 e 2.000.000, respectivamente..$^{3-5}$

O folículo ovariano é a unidade fundamental do ovário mamífero, consistindo de uma célula germinativa, o oócito, associada a células somáticas denominadas células da granulosa. ${ }^{6}$ De acordo com 
MAX, M. C. et al. Manipulação de oócitos inclusos em folículos ovarianos. / Manipulation of oocytes enclosed in ovarian follicles. / Manipulación de oocitos contenidos en folículos ováricos. Rev. Educ. Contin. CRMV-SP / Contin. Educ. J. CRMV-SP, São Paulo, v. 7 , n. $1 / 3$, p. $66-72,2004$.

o estágio de desenvolvimento, os folículos podem ser classificados como pré-antrais ou não-cavitários e antrais ou cavitários. Os folículos pré-antrais são caracterizados pela ausência da cavidade antral e podem ser divididos em folículos primordiais, primários e secundários. Dois tipos de folículos antrais podem ser distinguidos: os folículos terciários e os folículos préovulatórios, maduros ou de De Graaf (Figura 2).

Os folículos primordiais possuem um oócito circundado por uma camada de células da granulosa de forma pavimentosa. Nos bovinos, ovinos e caprinos, esses folículos possuem um diâmetro médio de $35,23 \mathrm{~mm} ; 18,00 \mathrm{~mm}$ e $21,50 \mathrm{~mm}$, respectivamente. ${ }^{4,7,8}$ Os folículos primários são caracterizados pela presença de uma única camada de células da granulosa de forma cúbica em torno do oócito, possuindo um diâmetro médio de $55,06 \mathrm{~mm}$ em bovinos, $35,01 \mathrm{~mm}$ em ovinos e 34,7 mm em caprinos. ${ }^{4,7,8} \mathrm{Já}$ os folículos secundários possuem um oócito circundado por duas ou mais camadas de células da granulosa de forma cúbica. Quando duas a três camadas de células da granulosa são formadas, as células da teca podem ser visualizadas em torno da membrana basal podendo ser identificada uma membrana hialinizada denominada zona pelúcida. ${ }^{9,10}$ Os folículos secundários possuem um diâmetro que varia de $81 \mathrm{~mm}$ a 250 $\mathrm{mm}$ em bovinos e um diâmetro médio de $66,03 \mathrm{~mm}$ e $58,94 \mathrm{~mm}$ em ovinos e caprinos. ${ }^{4,7,8}$

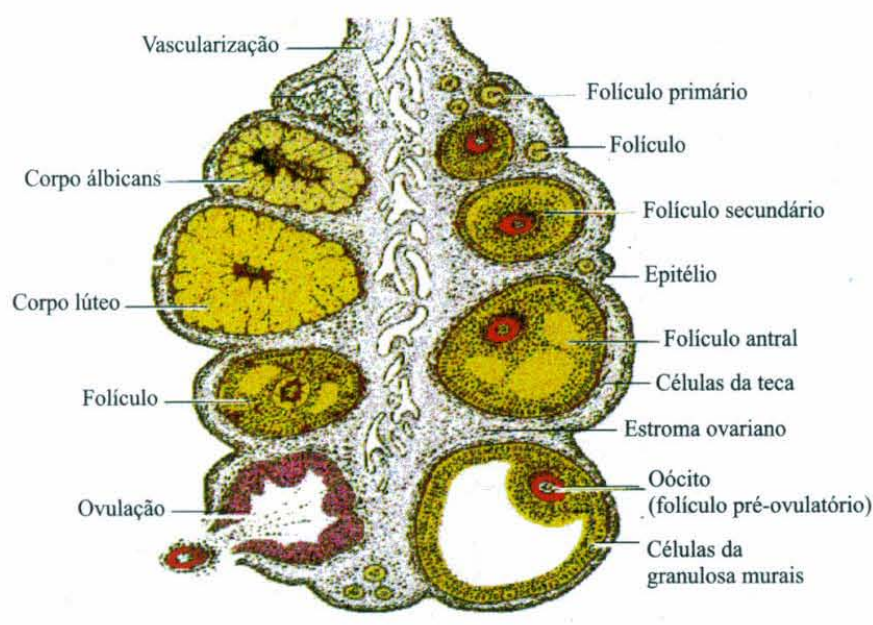

$\overline{\text { Figura } 2 \text { - Ilustração de um ovário com suas diferentes }}$ estruturas
Os folículos pré-antrais armazenam em torno de $90 \%$ dos oócitos presentes no ovário. ${ }^{11}$ No entanto, cerca de $99,9 \%$ dos folículos sofrem um processo fisiológico conhecido como atresia, que causa a morte do folículo, por via degenerativa e/ou apoptótica. ${ }^{10,12}$ Considerando a quantidade mínima desses folículos que se desenvolve até o estágio de folículo préovulatório, a biotécnica de MOIFOPA objetiva recuperar os oócitos inclusos nesses folículos e cultivá-los in vitro até sua completa maturação - em processo contínuo ou interrompido - pela criopreservação. . $^{13,14}$

\section{Métodos de Isolamento In Vitro de Oócitos Inclusos em Folículos Ovarianos Pré-Antrais}

O isolamento de folículos ovarianos préantrais pode ser feito de duas maneiras, uma mecânica e outra enzimática. Esses métodos consistem na dissociação ou separação destes folículos dos demais componentes do estroma ovariano (fibroblastos, fibras colágenas e elásticas, fibronectina, etc.). Para isso, são utilizados instrumentos mecânicos associados ou não aos químicos ou enzimáticos. ${ }^{11}$

A Tabela 1 mostra o número médio de FOPA isolado por ovário usando os métodos mecânico e/ou enzimático. ${ }^{4,8,15-17}$

Tabela 1 - Número médio de folículos ovarianos pré-antrais isolados nas diferentes espécies

\begin{tabular}{|cccc|}
\hline Espécie & $\begin{array}{c}\text { Ne de } \\
\text { folículos }\end{array}$ & Categoria & Autor \\
\hline Bovino & 2.142 & $\begin{array}{c}\text { Fêmea } \\
\text { em fase fetal } \\
\text { Novilha } \\
\text { Vaca }\end{array}$ & Figueiredo et al. ${ }^{17}(1992)$ \\
\hline Ovino & $\begin{array}{c}512 \\
298\end{array}$ & $\begin{array}{c}\text { Fêmea em } \\
\text { fase fetal } \\
\text { Ovelha }\end{array}$ & Carambula et al. ${ }^{16}(1996)$ \\
\hline Humano & 760 & $\begin{array}{c}\text { Jovens } \\
\text { Adultas }\end{array}$ & Amorim et al. ${ }^{8}(1999)$ \\
\hline Caprino & 10.140 & Cabra & Lucci et al. ${ }^{4}(1999)$ \\
\hline
\end{tabular}

Fonte: adaptado de Figueiredo et al. ${ }^{11}$ 
MAX, M. C. et al. Manipulação de oócitos inclusos em folículos ovarianos. / Manipulation of oocytes enclosed in ovarian follicles.

\section{Criopreservação de Oócitos Imaturos Inclusos em FOPA}

A criopreservação de FOPA vem sendo considerada uma alternativa para a estocagem de um grande número de oócitos imaturos de um único animal, ou mesmo para preservar material genético de mulheres submetidas à quimio e/ou radioterapia.

Outro aspecto importante da criopreservação de oócitos imaturos é a capacidade de aqueles serem menos susceptíveis à crioinjúria em razão de suas características. Dentre elas, as mais relevantes são: o menor tamanho do oócito, bem como das células da granulosa, sua baixa taxa metabólica, estágio do ciclo celular (prófase I), ausência de zona pelúcida e de grânulos corticais periféricos e a pequena quantidade de lipídeos intracitoplasmáticos sensíveis às baixas temperaturas. ${ }^{18}$

Os oócitos oriundos de FOPA podem ser congelados de duas maneiras: in situ, ou seja, no interior do próprio tecido ovariano, e também após o isolamento oocitário. ${ }^{19,20}$ Estudos histológicos revelam que folículos pré-antrais presentes no tecido ovariano após a congelação e a descongelação apresentam-se morfologicamente normais. ${ }^{21}$

\section{Cultivo dos Folículos Pré-Antrais}

O cultivo in vitro de folículos ovarianos préantrais tem como objetivo permitir o desenvolvimento folicular, assegurando o crescimento e a maturação dos oócitos, bem como a multiplicação e posterior diferenciação das células da granulosa. A composição dos meios de cultivo para folículos ovarianos pré-antrais varia enormemente, em função do estudo realizado. ${ }^{11}$

O desenvolvimento de um eficiente sistema de cultivo artificial é um ponto crucial para a ativação in vitro desses folículos. A primeira e essencial etapa de crescimento folicular é denominada ativação. ${ }^{22}$ A ativação ocorre a partir dos folículos primordiais e constitui-se da passagem dos folículos do pool de reserva ou folículos quiescentes para o pool de folículos em crescimento (primário, secundário, terciário e/ou pré-ovulatório). ${ }^{23} \mathrm{O}$ primeiro sinal de ativação dos folículos primordiais é a retomada da proliferação das células da granulosa, ou seja, o folículo primordial, circundado por uma camada de células da granulosa de formato pavimentoso e cúbico, transforma-se em folículo primário, circundado por somente uma camada de células cubóides. ${ }^{24}$ Além da mudança da forma das células da granulosa, os volumes citoplasmático e nuclear do oócito aumentam consideravelmente. ${ }^{1}$

Importantes mudanças ocorrem nos folículos primordiais após a ativação, envolvendo tanto o oócito como as células da granulosa. No entanto, o estudo do início de crescimento de folículos primordiais depende da disponibilidade de marcadores sensíveis para detectar o início deste crescimento folicular. ${ }^{25} \mathrm{O}$ conhecimento sobre os fatores e mecanismos envolvidos na ativação dos folículos primordiais é escasso, mas admite-se que diferentes hormônios, gonadotrofinas, aminoácidos e fatores de crescimento estejam envolvidos. ${ }^{24,26}$

O FSH (hormônio folículo estimulante) é apontado como fator crítico regulador da função ovariana. A ligação do FSH ocorre nas células da granulosa e resulta em uma variedade de ações, tais como a estimulação da proliferação dessas células, síntese de esteróides e expressão de receptores para fator de crescimento epidérmico (EGF) e LH (hormônio luteinizante). ${ }^{27,28}$ A associação de EGF e FSH mostrou-se benéfica para o crescimento folicular e o acréscimo do desenvolvimento de oócitos na espécie caprina. ${ }^{29}$

A utilização de LH no cultivo in vitro de folículos pré-antrais é menos explorada, mas sua eficiência já foi reportada em camundongos. ${ }^{26} \mathrm{O} \mathrm{GH}$ (hormônio de crescimento) também tem se mostrado eficiente no desenvolvimento folicular in vitro, principalmente quando associado ao $\mathrm{FSH}$ ou a fatores de crescimento. ${ }^{30}$ 
Com relação aos meios de cultivo, a solução à base de água de coco (SBAC) é um meio rico em nutrientes e de baixo custo que tem sido utilizado com sucesso para a maturação de oócitos ${ }^{31}$ e cultivo de embriões bovinos ${ }^{32}$ e murídeos ${ }^{33} \mathrm{~A}$ solução à base de água de coco é composta de duas partes de água de coco filtrada, uma parte de citrato de sódio a $5 \%$ e uma parte de água ultrapura. ${ }^{34} \mathrm{~A}$ SBAC tem sido eficientemente utilizada para conservação de sêmen de várias espécies (humano, ${ }^{34}$ caprino, ${ }^{35}$ ovino, ${ }^{36}$ suíno, ${ }^{37}$ ), além de ter sido usada com bons resultados na conservação in situ de folículos pré-antrais caprinos $^{38}$ e ovinos. ${ }^{39}$

\section{Considerações Finais}

A MOIFOPA é uma biotécnica que possibilita a multiplicação de animais com alto valor zootécnico, mortos e mesmo aqueles em via de extinção. Outro aspecto é a formação de bancos de germoplasma por meio da criopreservação desses FOPA, e a possibilidade de utilizar a espécie ovina como modelo para estudos na reprodução assistida humana. Embora esta nova biotécnica venha sendo utilizada somente em pesquisa fundamental, sua utilização para multiplicação de animais ainda depende de mais estudos e busca de sistemas de cultivo especiais que proporcionem condições adequadas para o ótimo desenvolvimento de FOPA in vitro.

\section{Abstract}

Objective: To disclose a new biotechnique, listing some of its aspects and addressing its main stages, isolation, cryopreservation and culture of preantral follicles. Data Sources: The information was obtained from CAB, MEDLINE, PUBMED, Science Direct and CAPES Portal. Data Synthesis: The preantral follicles store about $90 \%$ of the oocytes within the ovary. The biotechnique described is based on recovering immature oocytes retained inside preantral follicles before atresia takes place. The cryopreservation of these cells enables the creation of germoplasm banks, preserving the genetic material of women submitted to chemotherapy and/or radiotherapy, as well as that of endangered animal species. Conclusions: Being a recent biotechnique, its application is restricted to basic research. Additional studies are required to improve the stages involved.

Keywords: Biotechonology. Reproductive techniques. Oocytes, transplantation. Ovarian follicles. Cryopreservation.

\section{Resumen}

Objetivo: Divulgar la biotécnica exponiendo algunos de sus aspectos y abordar sus principales etapas, el aislamiento, la criopreservación y el cultivo. Fuentes Consultadas: La información se obtuvo de CAB, MEDLINE, PUBMED, Science Direct y el Portal CAPES. Síntesis de los Datos: Los folículos preantrales guardan aproximadamente el $90 \%$ de los oocitos que están presentes en el ovario. Esta biotécnica consiste en rescatar oocitos inmaduros retenidos en los folículos preantrales antes de que ocurra el proceso de atresia. Por la criopreservación de las células es posible constituir bancos de germoplasma, y preservar el material genético de mujeres que se sometieron a la quimio y/o radioterapia así como de animales en extinción. Conclusiones: Al ser una biotécnica reciente, sus aplicaciones se restringen a la investigación básica. Se requieren más estudios para perfeccionar sus etapas.

Palabras-clave: Biotecnología. Técnicas reproductivas. Oocitos, transplantación. Folículo ovárico. Criopreservación. 
MAX, M. C. et al. Manipulação de oócitos inclusos em folículos ovarianos. / Manipulation of oocytes enclosed in ovarian follicles. / Manipulación de oocitos contenidos en folículos ováricos. Rev. Educ. Contin. CRMV-SP / Contin. Educ. J. CRMV-SP, São Paulo, v. 7 , n. $1 / 3$, p. $66-72,2004$.

\section{Referências}

1. HIRSHFIELD, A. N. Development of follicles in the mammalian ovary. International Review of Cytology, v. 124, p. 43-101, 1991.

2. BETTERIDGE, K. J. et al. Potential genetic improvement of cattle by fertilization of fetal oocytes in vitro. Journal of Reproduction and Fertility, v. 38, p. 87-98, 1998.

3. ERICKSON, G. F. An analysis of follicle development and ovum maturation. Seminars in Reproductive Endocrinology, v. 4, p. 233-254, 1986.

4. LUCCI, C.M. et al. Effect of the interval of serial sections of ovarian issue in the tissue chopper on the number of isolated caprine preantral follicles. Animal Reproduction Science, v. 56, p. 39-49,1999.

5. DRIANCOURT, M. A. Follicular dynamics in sheep and cattle. Theriogenology, v. 33, p. 55-73, 1991.

6. TELFER, E. E. et al. In vitro development of oocytes from porcine and bovine primary follicles. Molecular and Cellular Endocrinology, v. 163, p. 117-123, 2000.

7. BRAW-TAL, R.; YOSSEFI, S. Studies in vivo and in vitro on the initiation of follicle growth in the bovine ovary. Journal of Reproduction and Fertility, v. 109, p.165-171, 1997.

8. AMORIM, C. A. et al. Mechanical method for the isolation of preantral follicles from adult ovine ovaries. In: REUNIÃO ANUAL DA SOCIE-DADE BRASILEIRA DE TRANSFERÊNCIA DE EMBRIÕES, 13., 1999, Atibaia. Anais... São Paulo: Sociedade Brasileira de Transferência de Embriões, 1999. p. 215.

9. SCARAMUZZI, R.J. et al. A model for follicle selection and the determination of ovulation rate in the ewe. Reproduction and Fertility Development, v. 5, p. 459-478, 1993.

10. FIGUEIREDO, J. R. Isolement, caractérisation et culture et follicules préantroux chez les bovins. Liege, 1995. $113 \mathrm{f}$. These (PhD- Université de Liège), Liège, 1995.

11. FIGUEIREDO, J. R.; RODRIGUES, A. P. R.; AMORIM, C. A. Manipulação de oócitos inclusos em folículos ovarianos pré-antrais. In: GONÇALVES, P. B. D.; FIGUEIREDO, J. R.; FREITAS, V. J. F. Biotécnicas aplicadas à reprodução animal. São Paulo: Varela, 2001. p. 227-260.

12. SAUMANDE, J. Ovogenèse et folliculogenèse. Recueill de Medècine Véterinaire, v. 157, p. 2938,1981 .

13. EPPIG, J. J.; O'BRIEN, M. J. Development in vitro of mouse oocytes from primordial follicles. Biology of Reproduction, v. 54, p. 197-207, 1996.

14. AMORIM, C. A. et al. Quantitative and qualitative analysis of the efficiency of the mechanical method for the isolation of preantral follicles from ovine ovaries. Theriogenology, v. 53, p. 1251-1262, 2000.

15. ROY, S. K., TREACY, B. J. Isolation and long-term culture of human preantral follicles. Fertility and Sterility, v. 59, p. 783-790, 1993.

16. CARAMBULA, S. F. et al. Dissociação mecânica e enzimática de ovários de fetos bovinos para o isolamento de folículos pré-antrais. Arquivos da Faculdade de Veterinária da UFRGS, v. 24, p. 235, 1996. Suplemento.

17. FIGUEIREDO J. R. et al. Mechanical and enzymatic method for the isolation of intact preantral follicles from fetal, calf and adult ovaries. REUNION AETE, 8., 1992, Lyon. Annales... Lyon: Association Européenne de Transfert Embryonnaire, 1992. v. 8, p. 152.

18. SHAW, J. M.; ORANRATNACHAI, J. M.; TROUNSON, A. O. Fundamental criobiology of mammalian oocytes and ovarian tissue. Theriogenology, v. 53, p. 59-72, 2000.

19. CANDY, C. J.; WOOD, M. J.; WHITTINGHAN, D. G. Effect of cryoprotectants on the survival of follicles in frozen mouse ovaries. Journal of Reproduction and Fertility, v. 110, p. 11-19, 1997.

20. JEWGENOW, K. et al. Viability of small preantral ovarian follicles from domestic cats after cryoprotectant exposure and cryopreservation. Journal of Reproduction and Fertility, v. 112, p. 39-47, 1998. 
21. HOVATTA, O. et. al. Cryopreservation of human ovarian tissue using dimethylsulphoxide and propanediolsucrose as cryoprotectants. Human Reproduction, v. 11, p. 1268-1272, 1996.

22. FORTUNE, J. E. et al. The primordial to primary follicle transition. Molecular and Cellular Endocrinology, v. 163, p. 53-60, 2000.

23. RÜSSE, I. Oogenesis in cattle and sheep. Bibliotheca Anatomica, v. 24, p. 77-92, 1983.

24. Van den HURK, R.; BEVERS, M. M.; BECKER, J. F. In vivo and in vitro development of preantral follicles. Theriogenology, v. 47, p. 73-82, 1997.

25. WANDJI, S. A.; EPPIG, J. J.; FORTUNE, J. E. FSH and growth factor affect the growth and endocrine function in vitro of granulosa cells of bovine preantral follicles. Theriogenology, v. 45, p. 817-832, 1996.

26. WU, J. et al. Luteinizing hormone has a stage-limited effect on preantral follicle development in vitro. Biology of Reproduction, v. 63, p. 320-327, 2000.

27. JEWGENOW, K.; PITRA, C. Hormone-controlled culture of secondary follicles of domestic cats. Theriogenology, v. 39, p. 527-535, 1993.

28. CORTVRINDT, R. G.; SMITZ, J. E.; van STEIRTEGHEM, A. C. Assessment of the need for follicle stimulating hormone in early preantral mouse follicle culture in vitro. Human Reproduction, v. 12, p. $759-768,1997$.

29. SILVA, J. R. V. et al. Influences of FSH and EGF on primordial follicles during in vitro culture of caprine ovarian cortical tissue. Theriogenology, 2004. In press.

30. LIU, J. et al. Maturation of mouse primordial follicles by combination of grafting and in vitro culture. Biology of Reproduction, v. 62, p. 1218-1223, 2000.
31. BLUME, H. et al. Avaliação da água de coco na maturação de oócitos bovinos. Revista Brasileira de Reprodução Animal, v. 21, p. 72-75, 1997.

32. BLUME, H. et al. Uso da água de coco no cultivo de embriões bovinos. Revista Brasileira de Reprodução Animal, v. 21, p. 79-81, 1997.

33. BLUME, H.; MARQUES JÚNIOR, A. P. Avaliação da água de coco no cultivo e criopreservação de embriões murídeos. Revista Brasileira de Reprodução Animal, v. 18, p. 97-104, 1994.

34. NUNES, J. F. Utilização da água de coco como diluidor do sêmen de animais domésticos e do homem. Revista Brasileira de Reprodução Animal, v. 22, p. 109-112, 1998.

35. NUNES, J. F.; SALGUEIRO, C. C. M. Utilização da água de coco como diluidor do sêmen de caprinos e ovinos. Revista Científica de Produção Animal, v. 1, p. 17-26, 1999.

36. GUERRA, F. F. A.; NUNES, J. F. Fertilidade in vivo e avaliação in vitro do sêmen ovino resfriado e conservado em água de coco por 72 horas. Revista Brasileira de Reprodução Animal, v. 23, p. 287289, 1999.

37. TONIOLLI, R.; MESQUitA, D. S. M.; CAVALCANTE, S. G. Avaliação in vitro do sêmen suíno diluído em PBS e na água de coco in natura e estabilizada. Revista Brasileira de Reprodução Animal, v. 22, p. 198-201, 1998.

38. SILVA, J. R. V. et al. Effect of coconut water and Braun-Collins solutions at different temperatures and incubation times on the morphology of goat preantral follicles preserved in situ. Theriogenology, v. 54, p. 809-822, 2000.

39. ANDRADE, E. R. et al. Evaluation of saline and coconut water solutions in the preservation of sheep preantral follicles in situ. Small Ruminant Research, v. 43, p. 235-243, 2002. 